\title{
Need Analysis for Down Syndrome Children to Develop a Learning Material on Numbers with the Aid of Multimedia Technology
}

\author{
Josefina B. Janier, Afza Shafie, Mohd Faisal Taha, Nadrah Bt. Mohamad, Wan Fatimah Wan Ahmad, \\ and Rahmah Lob Yussof
}

\begin{abstract}
Down Syndrome (DS) is a common chromosomal abnormality in human and typically delay in cognitive ability and physical growth. This study investigated the skills of $19 \mathrm{DS}$ children ages between 1-13 attending special sessions at Kiwanis Down Syndrome Foundation center at Ipoh, Perak. A 34 item survey checklist with 1-4 in the Likert scale was used and defined as 1-Never to 4-Always. The skills were categorized into cognitive, affective and psychomotor. From the responses of the teacher-in-charge and the parents, the results showed that the DS children have varied skills that can further be improved in order for them to become more independent. The identified skills were used as a bench mark in developing learning material on numbers from 1 to 10 using multimedia technology. The developed learning material is called SynMax and composed of 3 activities such as learning, matching and counting. It was based on some learning theories Dual Coding Theory and Schema Theory. The Synmax will be tested to the children with Down Syndrome to determine its suitability, for our future work.
\end{abstract}

Index Terms-Down syndrome, learning disabilities, multimedia technology.

\section{INTRODUCTION}

Down Syndrome (DS) known as trisomy 21, [1] and it is the most common chromosome abnormality in humans [2] typically associated with a delay in cognitive ability (mental retardation, MR), physical growth, and a particular set of key characteristics [1], [3]. These are : a) poor muscle tone or hypotonia; b) broad feet with short toes and a wide space between the big toe and the other toes; c) legs and arms are short in relation to rest of the body; d) tongue protrudes, mouth is small, lips are thin; e) ears are small, abnormally shaped and set low; f) face is flat; g) head is small; $\mathrm{h}$ ) small white patches can be seen on the edge of the iris of the eye; i) eye slit is narrow and short, fold skin at inner side of the eye and an upward and outward slant.

Despite the distinct features, (see Fig. 1) there is great diversity in terms of personality, intelligence, humor, learning style, compassion and attitude. They have varied

Manuscript received October 10, 2013; revised December 3, 2013.

Josefina B. Janier, Afza Shafie, and Mohd Faisal Taha are with the Fundamental and Applied Sciences Department Universiti Teknologi Petronas, Perak, Malaysia (e-mail: josefinajanier@petronas.com.my, afza@petronas.com.my, faisalt@petronas.com.my).

Nadrah Bt. Mohamad and Wan Fatimah Wan Ahmad are with the Department of Computer and Information Science Universiti Teknologi Petronas, Perak, Malaysia (e-mail: fatimhd@petronas.com.my, nad.modh@gmail.com).

Rahmah Lob Yussof is with the UITM, Pahang, Malaysia (e-mail: rahmah128@pahang.uitm.edu.my). emotions, are creative and imaginative in their own way, and can grow from the family and the community [4].

They should not be excluded from the community. Instead they can be helped and taught the necessary skills with different types of therapies, counseling and training in order to have some level of independence [5].

The average IQ of young adults with mild Down Syndrome is between IQ 50-70 and moderate Down Syndrome is IQ 35-50 whereas young adults without the condition typically have an IQ of 100 [6]. Also, DS has a speech delay and fine motor skills are delayed. They lag behind the gross motor skills and can interfere with cognitive development [7], [8]. According to Down Syndrome Ireland [9], delayed motor skills, auditory and visual impairment, postponement in speech and language, short term auditory memory, limited concentration span, difficulties with thinking and reasoning, and applying knowledge are the most common cognitive difficulties faced the people with DS. Because of this, it is critical to develop a proper frame -work that can cater most of the requirements of DS for them to acquire basic literacy skills and independence for use in their daily life interaction with their family and the community.
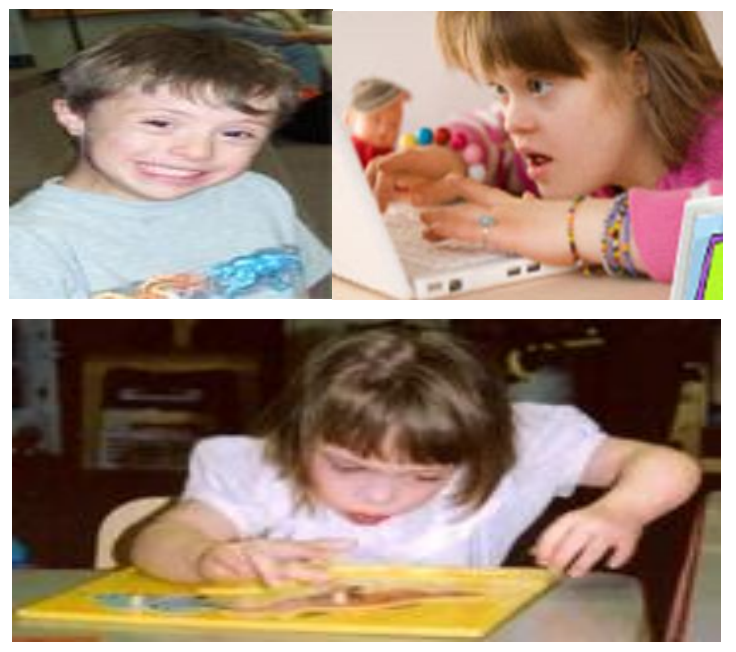

Fig. 1. DS children with notable features.

In 2009, one of the targets of the Malaysian government through the National Key Result Areas (NKRA) [1] is to broaden the access to affordable and quality education. In conjunction with the government's objective, a program, Literacy and Numeracy (LINUS) was implemented with the objective to ensure every child will be able to acquire basic literacy and numeracy skills after 3 years of mainstream primary education by the end of 2012. According to 
Performance Management and Delivery Unit (PEMANDU) [11] in Malaysia, the drop-out rate in 2008 was 31,939 at primary and secondary levels and one of the causes is because of learning disabilities such as Down Syndrome and Dyslexic.

In the context of inclusive education, i.e., giving the opportunity to learn, the researchers will identify the current skills of DS at different learning domains: cognitive, affective and psychomotor. Knowing their skills will guide the researchers to develop materials that can be used in teaching the DS children to develop their cognitive, affective and psychomotor abilities in order to cope in their daily life.

\section{LITERATURE REVIEW}

Learning disabilities is a neurological disorder that affects the brain's ability to receive and process information. It also pertains to person facing difficulty in acquiring basic intellectual skills which are fundamental for success at school, work and for coping with life in general. Some types of learning disabilities are DS, Dyslexic and Autism. Children with these learning disabilities are not able to follow the mainstream education system as they need customized learning methods that can suit their learning styles [10].

According to Dunnaway [12], children with disabilities lack the capability to listen, think, read or to perform mathematical calculations. Acquiring mathematical skills by DS children are poor compared to their functioning in other areas. Their achievements in literacy are far better than in mathematics.

A study investigated a range of short term memory skills and the effectiveness of memory training procedures in improving these skills. Using 63 children with DS, aged 4-18 years, from two geographical areas in United Kingdom, the study assessed each child on a battery of tests including short term memory skills in different modalities: language skills, speech rate, word identification and a number of general IQ measures. Two groups were formed, the experimental $(n=25)$ and the control $(n=26)$. Analysis verified that the 2 groups were similar and matched in terms of age and abilities. The initial assessment battery was repeated. The results showed that each training programme was effective and enhanced only those specific memory skills addressed [13].

According to McKinnon, it is crucial to provide mathematics curriculum that will prepare DS children to function independently. They need to acquire skills in money, time measurement and a basic understanding of number to function effectively in daily life [14].

For communication abilities, a study was done to a group of 6 DS children who attended an intervention programme. The age range is from 13 to 18 and has just been admitted for formal intervention. The children's ability in communication before and after the intervention was noted including their performance. Difficulties encountered by the DS children were discussed. Classroom observations and interviews were conducted with parents and teachers. A 15 item checklist based on language and social development skills was used. The observation method with their teacher, the DS were able to perform their tasks without behavior tantrums due to unfamiliarity. A 5-band profile scoring was used. The data showed the strengths and weaknesses of the children. It further showed that DS children can communicate to meet their personal needs although their degree of ability varied [15].

The perceptual - motor competence in school age DS children were found to be generally delayed. This was the result of assessing 22 DS children (13 males, 9 females) aged 4-14 years. Two standardized tests were used: the Movement Battery for Children (Movement ABC) for motor competence and Developmental Test of Visual - Motor Integration, a test focusing on copying shapes. Results showed that all the children scored below the $5^{\text {th }}$ percentile. However, despite delays, there were distinct variations in their tasks performed. Some gross motor function showed age development with delayed but regular acquisitions while fine motor skills assessed were more severely impaired and showed little development with age. Results suggest that intervention in the motor domain should be varied according to each child's particular profile of performance [16].

The above-mentioned studies have shown that DS children have varied capabilities and their learning skills can be identified through observation. Despite their disabilities, they also have their own strengths. For this paper, the identified skills of DS children at Kiwanis Down Syndrome Foundation Center (KDSFC), Ipoh will be a benchmark in order to develop learning materials that can assist them to be more independent and interact better to their family and community.

\section{Methodology}

\section{A. Reearch Method}

An exploratory type of research was used where a teacher-made questionnaire survey was done to gather data from parents and teacher at Kiwanis Down Syndrome Foundation (KDSF) Center at Ipoh, Perak. The center was established on September, 2006 by Kiwanis Club of Bandaraya Ipoh to educate the DS children ages 2 months old to 6 years old.

\section{B. Sample}

Nineteen (19) DS children between 1-13 years were observed and composed of 12 males and 7 females. The parents bring their DS children to attend a 2 hour session conducted by the teacher at the center.

Twelve (12) mothers and (1) teacher at KDSF responded to the survey questionnaire.

\section{Instrument}

Two observations checklists were prepared: one was answered by the teacher-in-charge and the other answered by the mothers of the DS children. In the teacher's checklist are 34 items which are classified as cognitive, affective, psychomotor and observable behavior problems of the children. The parents' checklist has 2 parts: Part A consist of 34 items classified into learning domain such as cognitive, affective, psychomotor, and observable behavioral problems and Part B questions concerning DS child's activities at home. Items in Part A of the checklist survey for the teacher and parents made use of a Likert scale of 1 to 4 with the following description: 1-never; 2- sometime; 3-often; and 4-always. 


\section{Statistics Used}

Mean and percent (\%) were used to determine the occurrence of performing the activity according to each domain as well as to find how often the behavioral problem occurs for each DS child.

\section{E. Mathematical Learning Material-SynMax}

The developed mathematical learning material is called SynMax. The user interfaces was developed using Adobe Flash CS5.5. The application tool "SynMax" was done to accommodate Bahasa Melayu and English language users.

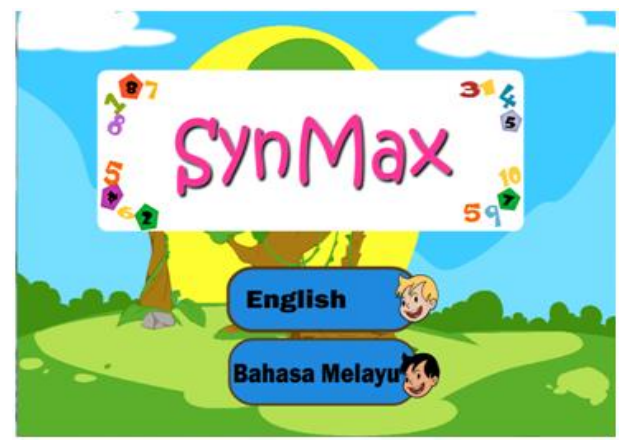

Fig. 2. The main page of the learning material.

The main idea is to teach children with DS to recognize number from 1 to 10 . There are mainly 3 activities which are "Learning", "Counting" and "Matching". The users can choose whether to do activities starting from 1 until 5 or 1 to 10. Fig. 2 shows the Main page of the application. In this page, users will be able to choose between English or Malay language by clicking either one of the buttons. After the language had been chosen, users can do activities from number 1 to 5 or 1 to 10 .

After that, users will be directed to Menu page, Figure 3 to choose between the "Learn", "Match", or "Count". The 3 modules are: "Learn" module where this will teach students to recognize numbers, "Match" module where this will allow the children to match the numbers and their shape; and "Count" module where it will teach the children about the value or amount for each of the number.

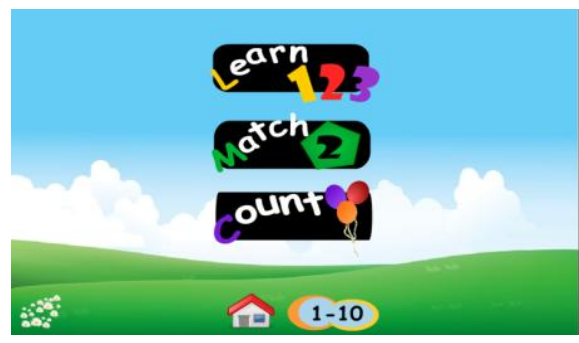

Fig. 3. The menu page of SynMax.

\section{RESULTS AND DISCUSSIONS}

The mean responses by the teacher in Table I are according to age brackets of DS children i.e., 10-13; 7-9; 4-6 and 1-3 years old respectively. Shown in Column 1 are the categories in the survey questionnaire. For age bracket 10-13, Psychomotor is the highest 3.35 (83.8\%) i.e., proper eating, sitting, pencil holding, coloring, dressing up andputting things in order. Affective is 3.19 (79.8\%), i.e., confidence, happiness, relating to others, attention and cleanliness. Finally, Cognitive $3.14 \quad(78.5 \%)$, i.e., recognition, remembering, conversing, counting, doing task with simple instruction. For age bracket 7-9, Affective is the highest 2 (50\%), followed by Psychomotor $1.9(47.5 \%)$, and Cognitive $1.45(36.5 \%)$. As for 4-6 age bracket, Affective is the highest $3.02(75.5 \%)$, Cognitive $2.61(65.25 \%)$ and Psychomotor, $2.43(60.75 \%)$. For 1-3 age bracket, Affective 2.54 (63.5\%), Cognitive 1.74 (43.5\%) and Psychomotor 1.7 (42.5\%).

According to the teacher, occurrence of behavioral problems is between $1.29(32.25 \%)$ to $2(50 \%)$.From the parents' views, (see Table II) is between 1.67 (41.75\%) to 2.7 $(67.5 \%)$ which is higher compared to the teacher's response. The reason could be the DS children only stay 2 hours per day at the center as compared to staying longer at home. This means that DS children do show their anxiety (nervous) with repetitive behavior and withdraw from peers or family members.

TABLE I: MEAN Results ACCORDING to AgE BRACKET BY THE TEACHER

\begin{tabular}{|l|l|l|l|l|}
\hline $\begin{array}{l}\text { Classification } \\
\text { of Items }\end{array}$ & $\begin{array}{l}\text { Age } \\
10-13\end{array}$ & $\begin{array}{l}\text { Age } \\
7-9\end{array}$ & $\begin{array}{l}\text { Age } \\
4-6\end{array}$ & $\begin{array}{l}\text { Age } \\
1-3\end{array}$ \\
\hline Cognitive & $\begin{array}{l}3.14 \\
(78,5 \%)\end{array}$ & $\begin{array}{l}1.45 \\
(36.3 \%)\end{array}$ & $\begin{array}{l}2.61 \\
(65.3 \%)\end{array}$ & $\begin{array}{l}1.74 \\
(43.5 \%)\end{array}$ \\
\hline Affective & 3.19 & 2 & 3.02 & 2.54 \\
& $(79.8 \%)$ & $(50 \%)$ & $(75.5 \%)$ & $(63.5 \%$ \\
\hline Psychomotor & 3.35 & 1.9 & 2.43 & 1.7 \\
& $(83.8 \%)$ & $(47.5 \%)$ & $(6.8 \%)$ & $(42.5 \%)$ \\
\hline $\begin{array}{l}\text { Behavioral } \\
\text { Problem }\end{array}$ & 1.8 & 2 & 1.75 & 1.29 \\
& $(45 \%)$ & $(50 \%)$ & $(43.7 \%)$ & $(32.2 \%)$ \\
\hline$N=19$ & $n=2$ & $n=2$ & $n=8$ & $n=7$ \\
\hline
\end{tabular}

TABLE II: RESUlTS ACCORDING TO AGE BRACKET BY THE PARENTS

\begin{tabular}{|l|l|l|l|l|}
\hline $\begin{array}{l}\text { Classification } \\
\text { of Items }\end{array}$ & $\begin{array}{l}\text { Age } \\
10-13\end{array}$ & $\begin{array}{l}\text { Age } \\
7-9\end{array}$ & $\begin{array}{l}\text { Age } \\
4-6\end{array}$ & $\begin{array}{l}\text { Age } \\
1-3\end{array}$ \\
\hline Cognitive & 3.25 & 2.65 & 1.68 & 2.03 \\
& $(81.25 \%)$ & $(66.3 \%)$ & $(42 \%)$ & $(50.8 \%)$ \\
\hline Affective & 2.78 & 2.66 & 2.82 & 2.56 \\
& $(69.5 \%)$ & $(66.5 \%)$ & $(70.5 \%)$ & $(64 \%)$ \\
\hline Psychomotor & 2.55 & 2.4 & 2.67 & 2.27 \\
& $(63.8 \%)$ & $(60 \%)$ & $(66.8 \%)$ & $(56.8 \%)$ \\
\hline Behavioral & 2.6 & 2.7 & 1.88 & 1.67 \\
Problem & $(65 \%)$ & $(67.5 \%)$ & $(47 \%)$ & $(41.8 \%)$ \\
\hline$N=12$ & $n=2$ & $n=2$ & $n=5$ & $n=3$ \\
\hline
\end{tabular}

Only 12 checklists were returned by the parents. Based on the learning domains, for 10-13 age bracket the highest mean is Cognitive with a mean of $3.25(81.25 \%)$, Considering that it is more than $75 \%$, it means that they can recognize, remember, converse, count and able to do simple tasks given simple instruction by the parents or other member of the family. For age brackets 7-9, 4-6, and 1-3, Affective garnered the highest mean which are $2.66(66.5 \%), 2.82(70.5 \%)$ and $2.56(64 \%)$ respectively. This shows that the DS children can relate to other family members, happy and confident with their family.

On Part B of the parents' questionnaire survey, the following were the responses to questions relating to their DS children as shown in Table III.

It could be seen that DS children have many intellectual challenges whereby the teacher needs to find strategies so that they will progressively move up and never assume that 
the child is not capable of doing things. They could be helped using the right tools appropriate for their learning capabilities. Although DS children do not go beyond the intellectual capability of a normal developing 6 to 8 year old child [17], teachers must strive to help them.

TABLE III: PARENTS' RESPONSES TO QUESTIONS IN THE SURVEY Mothers gave birth to DS child at the age between 30-41years

Occurrence of tantrums by DS child between 3 to 4 times in a week.
Parents' wish that their DS child will be more independent.
For socialization, DS child is brought to family and community
gatherings.

Within the family, learning can start from early childhood where each member must boost the confidence of the DS child. Use of therapy (physical, speech, occupational) can be very useful for them to improve. Inclusion to the family and community gatherings can boost the DS child's self-confidence and should not be left out. Use patience and strategic intervention in guiding the DS child. Because of their short span of memory, talk slowly, use simple language and give simple instruction for them to do certain small task at home and at school.

In order to manage their behavior, whether in school or at home, use positive reinforcement for example, praise and giving cookie rather than punishment.

SynMax a learning material on numbers which made use of computer application software was developed to assist DS children to learn the number concepts. It will help the learner to know numerical series and the order of numbers. The initial stage of the development involves only single numbers from 1 to 10 . Three modules were considered: identifying numbers, matching and learn. The development of SynMax was based on the learning theories such as behaviorism, cognitism and constructivism together with Dual Coding Theory (Clark and Paivo, 1991). Dual Coding theory postulates that both visual and verbal information is used to represent information. The ability to code a stimulus two different ways increases the chance of remembering an item compared to if the stimulus was only coded one way. Schema theory is about concepts: objects and the relationships they have with other objects, situations, events and sequence of events.

\section{CONCLUSION}

The skills of 19 Down Syndrome children between ages of 1 to 13 were identified using a 34 item checklist. The items were classified according to learning domains such as cognitive, affective, psychomotor, and behavior problems. Using the Likert scale of 1 to 4 and defined as Never to Always, it was found out that they have varied skills that can further be improved. Like any normal child sometimes behavior problems occur in the school and at home.

Members of the family are supportive and wanting that their Down Syndrome children will be more independent.

As regards to improving the learning of numbers, SynMax, a multimedia learning material that was developed will be tested in order to assist the children with Down Syndrome to know, count and match numbers accordingly. This will be our future work.

\section{ACKNOWLEDGMENT}

The authors would like to thank the staff of Kiwanis Down Syndrome Foundation Center, Ipoh for their assistance in collecting the questionnaires. This research is funded by the Ministry of Higher Education (MOHE) Malaysia under Fundamental Research Grant Scheme (FRGS) 158-200-169.

\section{REFERENCES}

[1] G. Grant, P. Goward, P. Ramcharan, and M. Richardson, "Learning disability: A life cycle approach to valuing people," McGraw-Hill International, pp. 43-44, May 1, 2010.

[2] Amniocentesis-American pregnancy association. (Feb. 23, 2013). [Online]. Available: http://www.Americanpregnancy.org/prenatal testing/amniocentesis.html

[3] Key Characteristics of people with Down Syndrome. Special EdEDUC3026. (April 3, 2013). [Online]. Available: http://specialededuc3026. wikispaces.Com/*Key+characteristics + of $+p$ eople+with+Down+Syndrome

[4] Public Awareness Language Guidelines. National Down Syndrome Congress. (Oct. 7, 2010). [Online]. Available: http: //www.nds.center,org/resources /packages 4.php

[5] M. J. Sexton, S. M. Dolan, and D. Smith. (Nov. 18, 2010). Common theraphies, counselling and training for young people with down syndrome. Health and Fitness. 2009. [Online]. Available: http://wrongdiagnosis.pubs.Righthealth.com.topic/people\%20Down\% syndrome $?$ as $=$ clink $\& a c+1437 \& a f c=216864664 \& p=\& d q p$. cache $\cdot \bmod$ e+PMBypass\#xzz111tmHk8

[6] G. S. Liptak. (2008). Down Syndrome (Trisomy 21; Trisomy G). Merck Manual. [Online]. Available: http://www.merckmanuals.com/home/sec23/ch266/ch266b.html

[7] G. Bird and S. Thomas, "Providing effective speech and language therapy for children with Down syndrome in mainstream settings: A case example," Down Syndrome News and Update, vol. 2, no. 1, pp. 30-31, 2002.

[8] L. Kumin, "Comprehensive speech and language treatment for infants, toddlers, and children with Down syndrome," in Down Syndrome: A Promising Future, Together, T. J. Hassold and D. Patterson, Eds. New York: Wiley-Liss., 1998.

[9] Development of Fine Motor Skills in Down Syndrome. (July 3, 2012). [Online]. Available: http://www.about-down-syndrome.com/fine-motor-skills-in-down-sy ndrome.htm

[10] Developing Numeracy Skills. [Online]. Available: http://www.Downsyndrome. ie/index.php/general-educational-information/developing numeracy-skills

[11] Learning Disabilities. [Online]. Available: http://www.disability malaysia.com/index 2. php?type $=$ view $\&$ table + factsheet $\& i d=39$

[12] Literacy and numeracy. (2010). [Online]. Available: http://www.pelajaranperak.gov.my

[13] A. Dunnaway. Homeschooling Children with Down Syndrome. [Online]. Available: http://www.scribd.com/doc/30242645/Homeschooling-Childre-withDown-Syndrome

[14] I. Broadley and J. MacDonald, "Teaching short term memory skills to children with down Syndrome, down syndrome research and practice," Sarah Duffen Centre and Department of Psychology, University of Portsmouth, vol. 1, no. 2, pp. 56-62, 1993.

[15] C. Y. Lin, M. Wu, J. A. Bloom, I. J. Cox, and M. Miller, "Rotation, scale, and translation resilient public watermarking for images," IEEE Trans. Image Process., vol. 10, no. 5, pp. 767-782, May, 2001.

[16] C. Mackinnon. (2005). Numeracy and Mathematics Information Sheet DSA Consortium. Subbiah, Communication Abilities of Down Syndrome, Proceeding Seminar Penyelidikan Pendidikan IPG. [Online]. Available: http://ojs akna.net/index.php/spp/article/view/558

[17] M Spanò, E Mercuri, T Randò, T Pantò, A Gagliano, S Henderson, and F Guzzetta. (1999). Motor and perceptual-motor competence in children with down syndrome: Variation in performance with age, European journal of pediatric neurology EJPN official journal of the European Pediatric Neurology Society. [Online]. 3(1). pp. 7-13. Available: http://www.ncbi.nlm.nih.gov 
[18] V. Trix. (2013). Accomodation and Inclusion Strategies for Teaching Children with Down Syndrome, Bight Hub Education. [Online]. Available:

http://www.brighthubeducation.com/special-ed-inclusion-strategies/2 9680-teaching-strategies-for-children

Josefina Barnachea Janier graduated with B.Sc. in Mathematics from Mapua Institute of Technology in 1972. She finished her MAT in Mathematics from Manuel L. Quezon University, 1983 and acquired her
Doctor of Education major in Management from Philippine Normal University, 1993. She taught mathematics at the Technological University of the Philippines from 1973 to 2002, Manila Philippines. She transferred to Universiti Teknologi PETRONAS (UTP) in 2002, a private institution located in Perak, Malaysia. Currently, she is an Associate Professor at UTP and teaching engineering mathematics in the undergraduate level. She is a faculty of the Fundamental and Applied Sciences Department. Her research interests are multimedia in mathematics education, mathematical modeling and parasite-cell identification and classification. 